\title{
Fisiopatogenia, epidemiologia e diagnóstico laboratorial da candidemia
}

\author{
Phisiopathogenesis, epidemiology and laboratory diagnosis of candidemia
}

Muriel Padovani Giolo'; Terezinha Inez Estivalet Svidzinski

unitermos
Candidemia
Patogenicidade
Genotipagem
Fatores de virulência

\section{resumo}

Candidemia é a infecção da corrente sanguínea causada por leveduras do gênero Candida. As espécies mais comumente isoladas em amostras de sangue venoso de pacientes hospitalizados são C. albicans, C. tropicalis, C. parapsilosis, C. glabrata e C. krusei. A finalidade desse estudo é fornecer uma revisão sobre candidemia, mostrando aspectos importantes sobre etioepidemiologia, relação fungo/hospedeiro e diagnóstico laboratorial desta infecção sistêmica emergente. Durante o processo de estabelecimento da candidemia, a levedura participa ativamente, expressando diversos fatores de virulência, o que acaba por favorecer a patogênese da candidemia. Entre esses fatores, destacam-se produção de enzimas extracelulares, dimorfismo, síntese de hemolisinas, capacidade de adesão e formação de biofilme. Nos pacientes acometidos, a intervenção medicamentosa deve ser precoce para minimizar os riscos de complicações e de resistência microbiana, portanto um diagnóstico laboratorial eficiente se faz necessário. O estudo e o conhecimento desses fatores, associados à genotipagem, podem contribuir de maneira decisiva para a descoberta de novos fármacos que possam atuar como profiláticos e/ou terapêuticos em pacientes com candidemia ou em risco de desenvolvê-la.

abstract

Candidemia is a bloodstream infection caused by yeasts of the genus Candida spp. The most commonly isolated species in venous blood samples of hospitalized patients are: C. albicans, C. tropicalis, C. parapsiolosis, C. glabrata and C. krusei. This study aimed at providing a review of candidemia, showing some important aspects of etio-epidemiology, fungus/host relation, and laboratorial diagnosis of this emerging systemic infection. During the onset of candidemia, yeasts play a major role on several virulence factors, which ultimately promote its pathogenesis. Among them, it may be highlighted the extracellular enzyme production, dimorphism, hemolysin synthesis, adhesion ability and biofilm development. In infected patients, medicines must be administered in the early stages to minimize the risks of complications and antimicrobial resistance. Therefore, an efficient laboratory diagnosis is required. The study of these factors associated with genotype analysis may contribute decisively to the discovery of new substances that may have a preventive and/or therapeutic effect on patients with candidemia or prone to develop it. key words

Candidemia

Pathogenicity

Genotyping

Virulence factors

1. Mestre; professor assistente da Universidade Paranaense, Campus de Cascavel.

2. Doutora; coordenadora do programa de pós-graduação em Biocências Aplicadas à Farmácia.

Suporte financeiro: Fundação Araucária. 


\section{Introdução e proposição}

As infecções sistêmicas causadas por leveduras vêm aumentado muito nas últimas décadas, especialmente a partir de 1980, devido ao grande número de pacientes imunocomprometidos reconhecidos como de risco para essas infecções (neutropênicos, transplantados, diabéticos, aidéticos, entre outros). Paralelamente, o aprimoramento das técnicas de diagnóstico laboratorial contribuiu para o aumento do número de casos de fungemia no mundo. Segundo Martin et al. ${ }^{(39)}$, nos Estados Unidos, entre 1979 e 2001, houve um aumento de $207 \%$ nas infecções da corrente sanguínea causadas por fungos, e Candida foi o principal gênero envolvido.

Atualmente a candidemia é reconhecida como grave problema de saúde pública nas regiões subdesenvolvidas, mas também é preocupante nos países desenvolvidos. A gravidade da doença, associada a condições debilitantes do paciente, leva a um aumento do tempo de internação hospitalar, acarretando elevação nos custos socioeconômicos. Outro fator relevante é que as complicações clínicas decorrentes dessa doença são graves, refletindo em altas taxas de morbimortalidade. De acordo com Viudes et al.(63), a mortalidade atribuída direta ou indiretamente à candidemia é de $40 \%$ a $60 \%$.

Portanto, um diagnóstico precoce é fundamental para que o tratamento farmacológico seja rapidamente instituído, aumentando, assim, a probabilidade de cura. O diagnóstico laboratorial da candidemia é baseado no encontro de leveduras em amostras de sangue periférico. Para isolamento do agente é utilizada a hemocultura, realizada de preferência por métodos automatizados. A seguir os micro-organismos são identificados segundo suas características bioquímicas e morfológicas. O limitante é que a sensibilidade da hemocultura é baixa, em torno de $50 \%$, com elevado número de casos falsos negativos ${ }^{(4)}$.

O arsenal de antifúngicos disponíveis no comércio é restrito, por isso a indicação deve ser criteriosa, no sentido de evitar o surgimento de micro-organismos resistentes, o que muitas vezes acaba por dificultar a recuperação do paciente, aumentando os custos de hospitalização. Atualmente é reconhecido, no mundo todo, o aumento do número de leveduras resistentes aos antifúngicos usuais, portanto a utilização de métodos laboratoriais in vitro contribui para a classificação dos isolados em sensíveis ou resistentes, auxiliando o médico na escolha da terapêutica.

O objetivo deste estudo é fornecer uma revisão sobre candidemia enfocando aspectos importantes sobre etioepidemiologia, relação fungo/hospedeiro e diagnóstico laboratorial desta infecção sistêmica emergente.

\section{Revisão de literatura}

\section{Histórico}

Segundo Sidrim e Rocha ${ }^{(57)}$, a primeira documentação de leveduras do gênero Candida spp. como patógeno é atribuída a Langenbeck, que em 1839 observou e isolou, da cavidade oral de um paciente com afta bucal, um microorganismo, que atualmente é a mais importante levedura patogênica do homem, a Candida albicans.

Contudo, as doenças causadas por fungos começaram a ganhar notoriedade a partir das observações feitas pelo cientista Agostino Bassi no início do século XIX. Esse pesquisador, realizando vários ensaios, conseguiu demonstrar a relação de uma doença encontrada no bicho-da-seda, de causa desconhecida na época, com a presença de um fungo. Conseguiu, a partir disso, desencadear infecções em animais, e esses resultados permitiram ao pesquisador editar o livro Frontispício do trabalho, consagrando-o como o pai da micologia clínica ${ }^{(57)}$.

Porém, a micologia viveu um tempo de ostracismo, vindo a ressurgir como uma importante área médica a partir das décadas de 1970 e 1980 do século passado(34). Desse período em diante observa-se maior valorização do assunto, com inúmeras colaborações acerca do entendimento das infecções causadas por fungos. Houve também uma preocupação com a padronização internacional quanto à classificação taxonômica dos agentes. A somatória do conhecimento nessas duas linhas ampliou e favoreceu a troca de informações ao nível mundial sobre as infecções fúngicas, de modo que hoje os fungos estão entre os principais agentes de infecções em pacientes hospitalizados.

\section{Biologia e taxonomia do gênero Candida spp.}

As leveduras do gênero Candida podem ser encontradas em variados ecossistemas, como solo, alimentos, água, fazendo parte da microbiota de homens e animais. Esses micro-organismos degradam proteínas e carboidratos para obterem carbono e nitrogênio, elementos essenciais para seu desenvolvimento.

Devido a sua capacidade adaptativa, as leveduras podem desenvolver tanto na presença de oxigênio quanto em anaerobiose. Na maioria das vezes se reproduzem de maneira assexuada, por meio de estruturas denominadas 
conídios, entretanto algumas espécies se multiplicam sexuadamente.

Candida spp. São classificadas taxonomicamente no reino Fungi, divisão Eumycota, subdivisão Deuteromycotina, classe Blastomycetes, família Cryptococcacea. De acordo com Sidrim e Rocha ${ }^{(57)}$, o gênero Candida é o principal entre as leveduras patogênicas, compreendendo aproximadamente 200 espécies.

São micro-organismos comensais, que habitam primariamente o trato gastrointestinal, fazendo parte também da microbiota vaginal, da uretra e dos pulmões ${ }^{(4)}$. Entretanto, essas mesmas leveduras podem se tornar patogênicas, caso ocorra um desequilíbrio em sua relação com o hospedeiro, por isso são consideradas oportunistas. Essa transformação pode ser devida a comprometimento dos mecanismos de defesa do hospedeiro (extremos de idade, doença de base, imunossupressão) ou rompimento das barreiras anatômicas, como queimaduras, cateteres ou cirurgias invasivas ${ }^{(17)}$. O gênero Candida spp. é responsável por $80 \%$ dos casos de infecção fúngica sistêmica(1).

C. albicans é considerada a principal levedura patogênica oportunista por ser a espécie mais frequentemente isolada em humanos. Entretanto, nas últimas décadas tem sido observado significativo aumento de outras espécies: C. tropicalis, C. parapsilosis, C. krusei, C. glabrata, C. kefyr, C. norvegensis, C. rugosa, C. guilliermondii, C. lusitaniae, C. ciferrii, C. haemulonii, C. lipolytica, C. pulcherrima, C. catenulata, C. utilis, C. viswanathii e C. zeylanoides. Essas e outras espécies, conhecidas como não-albicans, têm sido cada vez mais implicadas em processos infecciosos humanos.

A candidemia é a infecção da corrente sanguínea causada por leveduras do gênero Candida spp. De acordo com Chang et al. ${ }^{(8)}$, as espécies mais comumente isoladas em amostras de sangue venoso de pacientes hospitalizados são C. albicans, C. tropicalis, C. parapsilosis e C. glabrata.

\section{Candidemia hospitalar}

As infecções da corrente sanguínea (septicemia de origem bacteriana ou fúngica) representam importante problema de saúde pública mundial. São doenças de alta gravidade; acarretam aumento do tempo de internação hospitalar e consequentemente elevam os custos de hospitalização, além das elevadas taxas de morbimortalidade encontradas nos pacientes acometidos. Estudos estimam que a taxa de mortalidade da candidemia seja de $40 \%$ a $60 \%(9,63)$. Nos Estados Unidos, Gudlaugsson et al.(26) registraram, no período de 1997 a 2001, a taxa de mortalidade bruta de $61 \%$, e de mortalidade atribuída à candidemia, $49 \%$.

Entre pacientes hospitalizados e gravemente doentes, a sepse ainda é a principal causa de óbito. Nos EUA, no período de 1979 a 2000, houve um aumento significativo de casos anuais desta infecção, passando de $164 \mathrm{mil}(82,7 / 100$ mil pacientes) para 660 mil (240/100 mil pacientes). Neste mesmo período a prevalência de infecção da corrente sanguínea causada por fungos aumentou na ordem de $207 \%{ }^{(39)}$.

Atualmente vários estudos têm demonstrado a importância das leveduras do gênero Candida spp. como agentes de septicemia. Nos Estados Unidos, Edmond et al. ${ }^{(21)}$, analisando a prevalência de infecções da corrente sanguínea durante três anos, em 49 hospitais, observaram que Candida spp. foi a quarta causa mais comum de infecções de corrente sanguínea, responsável por 7,6\% dos casos, superada apenas por estafilococos coagulase-negativa (ECN) $(31,9 \%)$, Staphylococcus aureus (15,7\%) e Enterococcus spp. (11,1\%).

No Brasil foram encontrados resultados semelhantes. Entre outros, destaca-se um estudo epidemiológico conduzido por Colombo et al.(10), realizado em 11 hospitais terciários. Foram confirmados 712 casos de candidíase sistêmica. Candida spp. foi também o quarto patógeno mais frequentemente isolado, precedida por ECN, S. aureus e Klebsiella pneumoniae. O mesmo grupo de pesquisadores ${ }^{(11)}$, em estudo envolvendo resultados de 45.468 hemoculturas de quatro hospitais terciários de São Paulo, observaram que em $4 \%$ dos casos o agente isolado foi Candida spp.

Em relação à distribuição por espécies, segundo Colombo e Guimarães ${ }^{(9)}, C$. albicans foi a mais isolada de fungemias até a década de 1990. Após esse período foi observado um incremento na proporção de espécies não albicans. Em princípio, esse fato se deve à pressão seletiva exercida pelo uso profilático de fluconazol em pacientes com risco elevado de desenvolver infecções fúngicas invasivas ${ }^{(59)}$. Estudo realizado em hospitais terciários de Recife-PE comprovou que $C$. não albicans são as principais leveduras isoladas de fungemia e mostrou a importância da C. tropicalis em infecções fúngicas nosocomiais(27).

\section{Fatores de risco do hospedeiro}

As leveduras são encontradas em diversos sítios biológicos de homens e animais, em uma relação comensal com esses hospedeiros. Contudo, qualquer rompimento desse equilíbrio pode modificar essa relação harmônica e estabelecer outra, do tipo parasitário, que leva a infecções de diferentes gravidades. 
Inúmeros fatores ligados ao hospedeiro têm sido relacionados como facilitadores para o desenvolvimento de infecções fúngicas invasivas. Entre os mais importantes estão uso de antibióticos de largo espectro, tempo prolongado de internação hospitalar, neutropenia, nutrição parental, sonda vesical, ventilação mecânica, cateter venoso central e colonização de vários sítios anatômicos por leveduras.

Segundo Pappas et al. ${ }^{(50)}$, além desses fatores, outros merecem ser destacados, como idade extrema, imunossupressão, insuficiência renal, diabetes, quimioterapia, radioterapia, lesão de mucosas, hemodiálise, cirurgia prévia e corticoterapia.

\section{Fisiopatogenia}

As infecções causadas por leveduras do gênero Candida são denominadas candidíase ou candidose. As micoses causadas por esses fungos mostram um amplo espectro de apresentações clínicas, podendo ser classificadas desde superficiais, com acometimento cutâneo e mucoso, até infecções profundas, disseminadas, de alta gravidade, como é o caso da candidemia.

De acordo com Colombo e Guimarães ${ }^{(9)}$, o principal mecanismo de transmissão da candidemia é por via endógena, em que espécies de Candida que constituem a microbiota de vários sítios anatômicos, sob condições de debilidade do hospedeiro, comportam-se como patógenos oportunistas.

Outro mecanismo para transmissão é por via exógena, a qual ocorre principalmente por meio das mãos de profissionais da saúde que cuidam dos pacientes. Também estão arrolados materiais médico-hospitalares, como cateteres e soluções intravenosas que estejam contaminadas por fungos ${ }^{(22)}$.

\section{Fatores de virulência}

Há algumas décadas acreditava-se que as leveduras participavam passivamente do processo de patogênese no estabelecimento da infecção fúngica. Assim, a debilidade orgânica ou imune do hospedeiro era considerada o único mecanismo responsável para o estabelecimento da infecção oportunista. Atualmente esse conceito vem sendo modificado. É consenso que esses micro-organismos participam ativamente do processo fisiopatogênico da doença, utilizando-se de mecanismos de agressão denominados fatores de virulência ${ }^{(60)}$.

De acordo com Calderoni e Fonzi ${ }^{(7)}$, os principais fatores de virulência das leveduras são: capacidade de expressão de enzimas extracelulares, fosfolipases e proteinases, que degradam os tecidos do hospedeiro; produção de substâncias tóxicas que causam lesão celular; capacidade de adesão a células e tecidos; formação de biofilmes sobre células e superfícies inanimadas; produção de tubo germinativo por algumas espécies de Candida spp.; produção de hemolisinas; hidrofobicidade da superfície celular e resistência ao peróxido de hidrogênio.

Entretanto, acredita-se que haja uma ação sinérgica entre vários mecanismos de agressão, os quais, em associação à debilidade na resposta do hospedeiro, podem conduzir à candidíase.

\section{Proteinases e fosfolipases}

As leveduras são capazes de secretar enzimas extracelulares que destroem as membranas celulares do hospedeiro, favorecendo posterior invasão tecidual(24). As principais enzimas produzidas tanto por C. albicans quanto não albicans são as proteinases e fosfolipases.

As fosfolipases são um grupo de enzimas cuja secreção, em C. albicans, é regulada pelo gene PLB1. Esta expressão é afetada por fatores nutricionais, condições do ambiente (temperatura e $\mathrm{pH}$ ) e fase de crescimento da levedura. Fosfolipídios presentes na membrana das células humanas e animais são os substratos ${ }^{(47)}$.

As proteinases são reguladas por uma família de genes SAP. Possuem atividade proteolítica, ou seja, usam proteínas como substrato. Degradam colágeno, queratina, peptídeos localizados na superfície de mucosas e podem, ainda, atuar sobre componentes do sistema imunológico, como imunoglobulinas, complemento e citocinas, facilitando a invasão das leveduras aos tecidos do hospedeiro(33).

Diversos estudos têm demonstrado a relação entre o aumento na síntese e a atividade das enzimas extracelulares fosfolipases e proteinases, com a elevação do potencial patogênico das leveduras, levando a quadros clínicos de candidíases mais graves $(14,25,28,41)$.

\section{Atividade hemolítica}

Ainda pouco se discute sobre a atividade hemolítica das diferentes espécies de Candida ${ }^{(36)}$.

O elemento inorgânico ferro é indispensável no desenvolvimento dos micro-organismos em geral, inclusive das leveduras, e a obtenção desse elemento é essencial para o estabelecimento de um processo infeccioso. Nos seres humanos, a maior parte do ferro está armazenada intracelularmente como ferritina ou complexado ao grupamento heme. Uma pequena quantidade de ferro extracelular está 
ligada a proteínas de transporte de ferro, a transferrina e a lactoferrina ${ }^{(38)}$.

Portanto, os micro-organismos necessitam de mecanismos para captação de ferro para o seu desenvolvimento. A atividade hemolítica expressa a capacidade da levedura em destruir as hemácias com a finalidade de obter ferro.

A destruição dos eritrócitos pelas leveduras é realizada pela produção de substâncias denominadas hemolisinas ${ }^{(37)}$. O padrão de hemólise produzido pelas diversas espécies de Candida pode ser classificado em dois tipos: hemólise incompleta ou parcial e hemólise completa ou total(36,64).

Rorig et al. ${ }^{(55)}$ demonstraram que $C$. albicans tem maior capacidade hemolítica que as demais espécies analisadas (C. glabrata, C. parapsiolosis, C. tropicalis, C. guilhermondii e C. krusei). Por outro lado, Negri et al. ${ }^{(42)}$ mostraram que todas as amostras de $C$. tropicalis isoladas de hospitais produziram hemólise total. Além disso, Favero ${ }^{(23)}$ descreveu um fator hemolítico presente em sobrenadantes de cultura de isolados clínicos de C. tropicalis, resistente ao calor $\left(100^{\circ} \mathrm{C}\right) \mathrm{e}$ à ação da pepstatina, sendo ainda identificado um possível gene envolvido, o CtHLP.

\section{Tubo germinativo e polimorfismo em Candida albicans}

A capacidade da levedura em alterar sua morfologia dependendo das condições de temperatura e do pH é denominada dimorfismo ou polimorfismo celular. Isso ocorre em C. albicans, que pode apresentar-se sob a forma arredondada denominada blastoconídio, ou formando pseudo-hifas ou hifas e micélios verdadeiros.

Estudos relatam que a produção das estruturas micelianas (hifas) eleva a capacidade de aderência da levedura aos tecidos do hospedeiro devido ao aumento da superfície de contato do mesmo, consequentemente facilitando a invasão tecidual e levando à disseminação das leveduras a órgãos internos do corpo humano ${ }^{(7,46)}$. Portanto, as hifas têm sido relacionadas com as formas mais virulentas, que possivelmente ocorrem devido à resposta de C. albicans ao estresse ambiental ${ }^{(7,46)}$.

Pseudo-hifa é outra estrutura morfológica observada em C. albicans, produzida durante sua reprodução por brotamento, na qual os brotos não se destacam da célulamãe, ocorrendo, então, um encadeamento de células, cuja forma lembra uma hifa ${ }^{(3)}$. O tubo germinativo é um prolongamento contínuo da célula-mãe leveduriforme produzido no início do processo de filamentação, sendo considerado uma forma de transição entre a levedura e o micélio.
Estudos sugerem que cada uma dessas formas contribui de alguma maneira para a virulência de $C$. albicans sobre os tecidos do hospedeiro ${ }^{(32)}$. A capacidade de alteração fenotípica morfológica é um dos mais importantes mecanismos encontrados na patogênese da candidíase. Consolaro et al. ${ }^{(12)}$ demonstraram que na candidíase vulvovaginal a produção de tubo germinativo foi significativamente maior no grupo das mulheres sintomáticas do que no das assintomáticas. Dambroso et al. ${ }^{(16)}$ também comprovaram o aumento da porcentagem de formação de tubo germinativo e do tamanho desta estrutura em C. albicans isoladas de um grupo de pacientes submetidos a tratamento de radioterapia.

\section{Capacidade de adesão}

A capacidade dos micro-organismos de aderirem a células, tecidos ou outro tipo de superfície, é um pré-requisito para a colonização de um determinado sítio e causa de uma subsequente infecção. Nesse contexto, de acordo com Calderon e Fonzi ${ }^{(7)}$, a adesão parece ter papel inicial e fundamental no estabelecimento e desencadeamento do processo infeccioso.

Para que ocorra adesão, o primeiro estágio depende da aproximação ou do contato inicial entre a parede celular da levedura e a superfície da célula do hospedeiro ou de materiais médico-hospitalares. Esse processo está condicionado à interferência de fatores biológicos e não biológicos.

Entre os principais fatores não biológicos são reconhecidas as interações químicas que ocorrem entre as macromoléculas, como as forças de Van der Walls, interações hidrofóbicas, eletrostáticas e pontes de hidrogênio ${ }^{(20)}$. Em relação aos fatores biológicos, a adesão é mediada por mecanismos moleculares específicos, principalmente por meio de proteínas chamadas de adesinas. Essas estruturas aumentam a capacidade do fungo em aderir a superfícies inanimadas ou células/tecidos animais(44).

Após a levedura aderir à superfície, novos micro-organismos costumam interagir, promovendo a formação de uma comunidade plural de seres microscópicos, em que há dependência metabólica de grau variável entre seus constituintes, caracterizando, assim, a estrutura conhecida como biofilme.

\section{Biofilme}

O biofilme é constituído por um conjunto de microorganismos distintos que convivem em associação. Nas 
últimas décadas, bacteriologistas e, mais recentemente, micologistas têm observado que os micro-organismos praticamente não existem na sua forma livre, planctônica nos tecidos do hospedeiro, mas se agrupam formando uma comunidade multicelular e plural, tanto sob os tecidos quanto em próteses, cateteres e outras superfícies ${ }^{(58)}$.

O primeiro evento imprescindível no processo de formação de biofilme é a adesão microbiana, à qual se segue o processo de maturação do biofilme ${ }^{(51)}$. Após a aproximação da levedura com o substrato, inúmeros acontecimentos físico-químicos tornam possível a adesão inicial do microorganismo a esta superfície. Finda a etapa de adesão, o biofilme sofre um processo de maturação.

Em um biofilme maduro coexistem muitas microcolônias, constituídas por distintas espécies de leveduras, que são envolvidas por uma matriz extracelular na qual ocorre a passagem de água e nutrientes. Segundo Douglas ${ }^{(19)}$, os biofilmes maduros com um crescimento de 24 a 48 horas consistem em uma rede densa de células sob a forma de leveduras, de hifas e pseudo-hifas, além da presença facultativa de bactérias.

Em suma, essa tendência natural dos micro-organismos a conviver em comunidade, formando biofilme, ocorre devido às vantagens conferidas quando está em associação. Entre os benefícios da comunidade destacam-se a maior proteção contra as defesas imunes do hospedeiro e a ação de antimicrobianos, o que acaba por favorecer o estabelecimento do processo patogênico. Além disso, a interação entre espécies fornece benefícios mútuos. Pádua et al. ${ }^{(48)}$ mostraram que a bactéria Pseudomonas aeruginosa teve maior capacidade de aderência a cateter urinário quando na presença de $C$. albicans.

\section{Identificação laboratorial das leveduras}

A partir de 1980, devido ao aumento do número de casos de candidemia em nível mundial, houve necessidade do aprimoramento das técnicas de diagnóstico laboratorial. Tendo em vista a gravidade das infecções fúngicas sistêmicas, bem como seu elevado custo socioeconômico, é importante um diagnóstico rápido e preciso para que a intervenção medicamentosa possa ser iniciada precocemente na tentativa de minimizar as elevadas taxas de mortalidade.

O diagnóstico clínico, com base na sintomatologia e na anamese do paciente, não é conclusivo, pois os sinais e sintomas são inespecíficos. Febre e leucocitose seriam os principais indícios de fungemia, porém $20 \%$ dos pacientes não desenvolvem hipertermia e apenas 50\% apresentam leucocitose ${ }^{(6)}$. Além disso, mesmo na presença desses sinais, não é possível supor uma candidemia considerando-se a semelhança com os sinais de bacteremia.

Assim, é imprescindível a confirmação laboratorial da candidemia por meio da técnica da hemocultura, a qual possui sensibilidade baixa, próxima de $50 \%$, o que resulta num diagnóstico tardio, aumentando as chances de complicação(4-6).

A identificação de leveduras é baseada em várias provas que avaliam as características morfológicas e bioquímicas desses micro-organismos. Alguns testes são utilizados rotineiramente: produção do tubo germinativo, microcultivo em ágar fubá-tween 80 , assimilação de carboidratos ou de nitrogênio (auxanograma) e fermentação dos carboidratos (zimograma) $)^{(34)}$.

Essas provas fazem parte dos métodos fenotípicos tradicionais para a identificação de leveduras usadas em laboratórios do mundo todo, considerados métodos clássicos e padrão ouro para essa finalidade.

A partir da década de 1990, surgiram meios de cultura cromogênicos que auxiliam na triagem de leveduras patogênicas, diferenciando as colônias conforme a cor produzida e facilitando a deteç̧ão de culturas mistas. Essa ferramenta pode também ser utilizada com o intuito de fornecer preliminarmente um laudo rápido para o clínico, para que a intervenção terapêutica seja imediata ${ }^{(40)}$.

Cada vez mais são colocados no mercado sistemas automatizados e semiautomatizados para facilitar a identificação das leveduras ${ }^{(56,61)}$. Contudo, o uso destas ferramentas é ainda extremamente limitado por várias razões: custo elevado, falta de tradição, falta de produtos no mercado nacional. Além disso, o princípio dessas "novas" metodologias é o mesmo dos testes manuais, o que acaba acomodando os laboratórios, com a justificativa de que as metodologias clássicas ainda são as referências para a identificação de fungos patogênicos.

Além dos métodos descritos anteriormente, novas estratégicas têm sido empregadas no diagnóstico laboratorial das candidemias. Métodos sorológicos, nos quais é avaliada a presença de antígenos ou anticorpos anti-Candida no soro, e aqueles que detectam constituintes da parede celular da levedura como manose e 1-3- $\beta$-D-Glucan ${ }^{(45)}$.

Devido às limitações decorrentes do uso das técnicas diagnósticas tradicionais, ainda há necessidade de desenvolvimento de outros métodos, que permitam um diagnóstico rápido, sensível, preciso e confiável. Nesse sentido, as técnicas moleculares como a reação em cadeia da polimerase $(P C R)^{(2)}$ podem ser uma boa opção. 


\section{Diagnóstico da candidemia por PCR}

O desenvolvimento e o aperfeiçoamento das técnicas de biologia molecular utilizando o DNA de agentes infecciosos têm-se mostrado uma estratégia clinicamente viável. A PCR é a técnica mais utilizada para este fim, pois permite rápida identificação de alguns fungos. Entretanto, para o diagnóstico da candidíase ainda não mostra razão positiva custo/eficácia em relação aos métodos clássicos.

Para fins epidemiológicos, a técnica derivada da PCR "amplificacão aleatória de DNA polimórfico", conhecida pela sigla na língua inglesa RAPD, fornece bons resultados. Esse ensaio utiliza uma sequência pequena (nove a 10 pares de bases) como primers aleatórios para a amplificação do DNA. Essa variação da PCR permite avaliar a correlação genética entre isolados da mesma espécie ${ }^{(30,35)}$. É uma das técnicas mais empregadas para esse propósito devido a sua facilidade de execução, muito utilizada para comparar isolados obtidos de amostras clínicas com os de fontes inanimadas, auxiliando na análise de inquéritos epidemiológicos de surtos hospitalares ${ }^{(52)}$.

Por esse método de genotipagem pode-se analisar a similaridade entre isolados clínicos e se micro-organismos da mesma espécie são iguais, similares ou diferentes, discriminando subpopulações intraespécies. Essa metodologia também tem aplicação para se demonstrar a provável origem daquela infecção fúngica. Por meio da tipagem molecular de micro-organismos isolados em colonização (mãos, superfícies dispositivos), e em comparação com isolados infectantes, pode-se comprovar se as mesmas são ou não geneticamente idênticas ${ }^{(31,62)}$.

As principais vantagens da RAPD-PCR em relação às demais técnicas moleculares são: rapidez de execução, baixo custo, facilidade de implantação em laboratórios, facilidade de aplicação em estudos epidemiológicos, além de não haver necessidade de se conhecer previamente o DNA a ser analisado ${ }^{(54,62) .}$

\section{Testes de suscetibilidade a antifúngicos}

Uma preocupação crescente na área microbiológica é o aumento do número de micro-organismos com resistência farmacológica, tanto frente aos antibacterianos quanto aos antifúngicos. A resistência às drogas é um grave problema de saúde, pois tem ocasionado vários surtos de infecções seguidos de morte. A resistência in vitro aos antifúngicos ainda é muito baixa, sendo primária em pouquíssimos casos. Entretanto, o uso profilático de antifúngicos em pacientes com maior risco de desenvolver infecções fúngicas invasivas tem alterado o perfil das leveduras. Um dos mais utilizados com esse fim em hospitais é o fluconazol, responsável, ao menos em parte, pela diminuição de infecções causadas por C. albicans (em geral mais sensíveis) e pelo aumento do número de espécies não albicans, especialmente C. glabrata e C. krusei, com perfil aumentado de resistência a esse antifúngico ${ }^{(10,59)}$.

Assim, nos dias atuais, os testes de suscetibilidade a antifúngicos são fundamentais para que o tratamento antifúngico seja conduzido de maneira segura, correta e eficaz. Pelo antifungigrama é possível monitorar e detectar cepas de Candida spp. resistentes, auxiliando o clínico na escolha terapêutica antifúngica adequada ${ }^{(29)}$. Entretanto, os testes laboratoriais disponíveis para fungos não têm a mesma contribuição que os usados para bactérias.

O método mundialmente reconhecido como de referência para antifungigrama foi padronizado pelo Clinical Laboratory Standards Institute (CLSI), em 1997, aperfeiçoado por meio de vários documentos posteriores. A metodologia, cujo princípio é o de diluição em caldo, apresenta boa reprodutibilidade, porém, além de ser muito trabalhosa, exige grande habilidade do manipulador devido aos detaIhes técnicos e dificuldade de leitura, sendo, portanto, de difícil aplicação rotineira na maioria dos laboratórios ${ }^{(15,53)}$.

$\mathrm{Na}$ tentativa de difundir o uso de técnicas de antifungigramas para maior número de laboratórios, sistemas comerciais alternativos como o $\mathrm{E}$ teste vêm apresentando boa correlação com a metodologia de referência. Uma das principais vantagens dessa técnica é o menor tempo de leitura (24 horas), enquanto o da diluição em caldo é de 48 horas, além da maior facilidade de execução ${ }^{(18,49)}$. Porém, o elevado custo e a dificuldade de acesso no comércio são pontos limitantes até o momento.

Alternativamente tem sido sugerido o teste de difusão em disco, que é um método fácil e mais barato. O critério de leitura é a medida das zonas de inibição do crescimento das leveduras da mesma forma que é feito para bactérias ${ }^{(43)}$. Por não utilizar variações de concentração de antifúngico e, consequentemente, não definir ponto de corte, os microorganismos são classificados apenas como sensiveis, sensiveis dose-dependentes e resistentes ${ }^{(13)}$. Além disso, o teste de difusão em disco não está totalmente validado para todos os antifúngicos e depende de otimização em sua metodologia.

\section{Considerações finais}

A candidemia é uma doença complexa, dependente de inúmeros fatores, além de altamente letal. Assim, torna-se 
fundamental conhecê-la melhor sob os vários aspectos. A determinação das características fenotípicas e genotípicas dos seus agentes permite a adoção de estratégias para tratamento, controle e prevenção. Também protocolos devem ser planejados e adotados, no sentido de diminuir as consequências da infecção da corrente sanguínea causada por fungos.

Outro ponto a ser destacado é o conhecimento dos mecanismos de virulência que as leveduras dispõem para desencadear infecções de caráter invasivo. Novos fármacos com ação específica devem ser pesquisados e descobertos, no sentido de minimizar a expressão desses fatores de virulência, consequentemente dificultando o desenvolvimento do processo infeccioso.

Testes de suscetibilidade a antifúngicos devem ser realizados apesar de, diferentemente dos antibacterianos, não serem uma prática clínica comum na área da microbiologia médica. Nesse contexto, reforçamos a necessidade da implantação de um programa para avaliação in vitro da suscetibilidade destes patógenos frente às drogas.
O monitoramento de amostras clínicas pode ser uma ferramenta extremamente útil, pois permitirá a escolha do fármaco adequado e da dose ideal, com base em critérios farmacológicos, a serem usados para cada paciente, evitando-se tanto a administração de dose excessiva, e consequentemente seus efeitos indesejáveis, como a seleção de micro-organismos resistentes.

Além da determinação de caracteres fenotípicos das leveduras, a genotipagem por RAPD pode avaliar possíveis fontes de surtos hospitalares e estabelecer identidade ou similaridade das linhagens presentes no ambiente hospitalar, ferramenta importante na epidemiologia hospitalar.

Finalmente, ampliar e divulgar conhecimentos sobre a candidemia é uma forma de disseminar a necessidade de se estabelecerem programas eficientes de farmacovigilância associados à determinação da suscetibilidade in vitro das leveduras dentro de um hospital, dados interessantes no sentido de controlar o aumento do número de casos de candidemia e, sobretudo, buscar a queda das taxas de mortalidade atribuída a esse agravo.

\section{Referências}

1. ABI-SAID, D. et al. The epidemiology of hematogenous candidiasis caused by different Candida species. Clin Infect Dis, v. 24, p. 1122-8, 1997.

2. AHMAD, $\mathrm{S}$ et al. Seminested PCR for diagnosis of candidemia: comparison with cultre, antigen detection, and biochemical methods for species identification. J Clin Microbiol, v. 40, p. 2483-9, 2002.

3. ALMEIDA, O. P.; SCULLY, P. Fungal infections of the mouth. Braz J Oral Sci, v. 1, p. 19-26, 2002.

4. ALONSO-VALLE, H. et al. Candidemia in terciary care hospital: epidemiology and factors influencing motality. Europ Clin Microbiol Infect Dis, v. 22, p. 254-7, 2003.

5. ARMSTRONG, D. Problems in management of opportunistic fungal diseases. Rev Infect Dis, v. 2, p. 1591-9, 1989.

6. BLOT, S. I. et al. Effects of nosocomial candidemia on outcomes of critically III patients. The Americ J of Med, v. 113, p. 480-5, 2002.

7. CALDERONI, R. A.; FONZI, W. A. Virulence factors of Candida albicans. Trends in Microbiol, v. 9, p. 327-35, 2001.

8. CHANG, M. R. et al. Candida bloodstream infection: data from a teaching hospital in Mato Grosso do Sul, Brazil. Rev Inst Med Trop, v. 50, p. 265-8, 2008.

9. COLOMBO, A. L.; GUIMARÃES, T. Epidemiology of hematogenous infections due to Candida spp. Rev Soc Bras Med Trop, v. 36, p. 599-607, 2003.

10. COLOMBO, A. L. et al. Epidemiology of candidemia in Brazil: nationwide sentinel surveillance of candidemia in eleven medical centers. J Clin Microbiol, v. 44, p. 2816-23, 2006.

11. COLOMBO A. L. et al. Prospective observational study of candidemia in São Paulo, Brazil: incidence rate, epidemiology, and predictors of mortality. Infect Control Hosp Epidemiol, v. 28, p. 570-6, 2007.

12. CONSOLARO, M. E. L. et al. Vulvovaginal candidiasis is associated with the production of germ tubes by Candida albicans. Mycopathologia, v. 159, p. 501-7, 2005.

13. CORMICAN, M. G.; PFALLER, M. A. Standardization of antifungal susceptibility testing. J Antimicrob Chemotherapy, v. 38, p. 561-78, 1996.

14. CORREA, P. C. et al. Caracterização fenotípica de leveduras isoladas da mucosa vaginal em mulheres adultas. Rev Bras Ginecol Obstet, v. 3, p. 177-81.

15. CUENCA-ESTRELLA, M. et al. Comparative evaluation of NCCLS M27-A and EUCATEST broth microdilution procedures for antifungal susceptibility testing of Candida species. Antimicrob Agents Chemother, v. 46, p. $3644-7$

16. DAMBROSO, D. et al. Radiotherapy effect on frequency of Candida spp. and on virulence of $C$. albicans isolated from the oral cavity of head and neck cancer patients. Rev Ciênc Farm Básica e Apl, v. 30, p. 25-32.

17. DIGNANI, M. C; SOLOMKIN J. S.; ANAISSIE, E. Candida. In: ANAISSIE, E.; McGINNIS, M. R.; PFALLER, M. A. (Ed.). Med mycology. 1. ed. Philadelphia: Churchill Livingstone, 2003. p. 195-239. 
18. DIEKEMA, J. D. et al. Evalution of E test and disk diffusion methods compared with broth microdilution antifungal susceptibility testing of clinical isolates of Candida spp. against posaconazole. J Clin Microbiol, v. 45, p. 1974-7, 2007.

19. DOUGLAS, J. L. Candida biofilms and their role in infection. Trends in Microbiol, v. 11, p. 30-6, 2004.

20. DUNNE, W. M. Bacterial adhesion: seen any good biofilms lately? Clin Microbiol, v. 15, p. 155-66, 2003.

21. EDMOND, M. B. et al. Nosocomial bloodstream infections in United States hospitals: a three-year analysis. Clin Infec Dis, v. 29, p. 239-44, 1999.

22. EGGIMAN, P.; GARBINO, J.; PITTET, D. Epidemiology of Candida species infections in critically ill nonimmunosupressed patients. Lancet Infect Dis, v. 3, p. 685-702, 2003.

23. FAVERO, D. Fator hemolítico em Candida tropicalis. Londrina, 2008. Dissertação (mestrado) - Programa de pós-graduação em Microbiologia da Universidade Estadual de Londrina.

24. FURLANETO-MAIA, L. et al. In vitro evaluation of putative virulence attributes of oral isolates of Candidaspp. obtained from elderly healthy individuals. Mycopathologia, v. 166, p. 209-17, 2008.

25. GACSER, A. et al. Targeted gene deletion in Candida parapsilosis demonstrates the role of secreted lipase in virulence. J Clin Invest, v. 117, p. 3049-958, 2007.

26. GUDLAUGSSON, O. et al. Attributable mortality of nosocomial candidemia, revisited. Clin Infect Dis, v. 37, p. 1172-7, 2003.

27. HINRICHSEN, S. L. et al. Candida isolates in tertiary hospitals in northeastern Brazil. Braz J Microbiol, v. 40, p. 325-8, 2009.

28. IBRAHIM, A. S. et al. Evidence implicating phospholipase as a virulence factor of Candida albicans. Infect Immun, v. 63, p. 1993-8, 1995.

29. KANAFANI, A. Z.; PERFECT, J. R. Resistance to antifungal agents: mechanisms and clinical impact. Clin Infect Dis, v. 469, p. 120-8, 2007.

30. KANBE, T. et al. PCR-based identification of pathogenic Candida species using primer mixes specific to Candida DNA topoisomerase II genes. Yeast, v. 19, p. 973-89, 2002.

31. KLEMPP-SELB, B.; RIMEK, D.; KAPPE, R. Karyotyping of Candida albicans and Candida glabrata from patients with Candida sepsis. Mycoses, v. 43, p. 159-63, 2000.

32. KUMAMOTO, C. A.; VINCES, M. D. Contributions of hyphae and hyphae-co-regulated genes to Candida albicans virulence. Cell Microbiol, v. 7, p. 1546-54, 2005.

33. KUMAR, G.; KUMAR, S. J.; MENON, T. Phospholipase and proteinase activities of clinical isolates of Candida from immunocompromised patients. Mycopathologia, v. 161, p. 213-8, 2006.

34. LACAZ, C. S. et al. Tratado de micologia médica: LACAZ. São Paulo: Sarvier, 2002. p. 34, 125.

35. LEHMANN, P. F.; LIN, D.; LASKER, B. A. Genotypic identification and characterization of species and strains within the genus Candida by using random amplified polymorphic DNA. J Clin Microbiol, v. 30, p. 3249-54, 1992.
36. LUO, G.; SAMARANAYAKE, L. P.; YAU, J. Y. Y. Candida species exhibit differential in vitro hemolytic activities. J Clin Microbiol, v. 1, p. 2971-4, 2001.

37. LUO, G. et al. Reverse transcriptase polymerase chain reaction (RT-PCR) detection of HPL gene expression in Candida glabrata and its possible role in in vitro haemolysin production. APMIS, v. 112, p. 283-90, 2004.

38. MANNS, J. M.; MOSSER, D. M.; BUCKLEY, H. R. Production of a hemolytic factor by Candida albicans. Infect and Immun, v. 62, p. 5154-6, 1994.

39. MARTIN, G. S. et al. The epidemiology of sepsis in the United States from 1979 through 2000. The New Eng J Med, v. 348, p. 1546-54, 2003.

40. MIMICA, L. M. J. et al. Diagnóstico de infecção por Candida: avaliação de testes de identificação de espécies e caracterização do perfil de suscetibilidade. J Bras Patol Med Lab, v. 45, p. 17-23, 2009.

41. MOHAN, V.; BALLAL, M. Proteinase and phospholipase activity as virulence factors in Candida species isolated from blood. Rev Iberoam Micol, v. 25, p. 208-10, 2008.

42. NEGRI, M. et al. Examination of potential virulence factors of Candida tropicalis clinical isolates from hospitalized patients. Mycopathologia, v. 169, p. 175-82, 2010.

43. NEGRI, M. et al. Correlation between Etest, disk diffusion and microdilution methods for antifungal susceptibility testing of Candida species from infection and colonization. J Clin Lab Anal, v. 23, p. 324-30, 2009.

44. NOBILE, J. C. et al. Complementary adhesin function in C. albicans biofilm formation. Curr Biol, v. 18, p. 1017-24, 2008.

45. OBAYASHI, T. et al. Plasma (1-->3)-beta-D-glucan measurement in diagnosis of invasive deep mycosis and fungal febrile episodes. Lancet, v. 345, p. 17-20, 1995.

46. ODDS, F. C. Pathogenesis of Candida infection. J American Academic Dermatol, v. 31, p. 2-5, 1994.

47. OMBRELLA, A. M.; RACCA, L.; RAMOS, L. Actividades proteinasa y fosfolipasa de aislamientos de Candida albicans provenientes de secreciones vaginales com distintos valores de pH. Rev Iberoam Micol, v. 25, p. 12-6, 2008.

48. PÁDUA, R. A. F. et al. Adherence of Pseudomonas aeruginosa and Candida albicans to urinary catheters. Rev Iber Micol, v. 25, p. 173-5, 2008.

49. PFALLER, M. A. et al. Clinical evaluation of the sensititre yeast one colorimetrical antifungal panel for antifungal susceptibility testing of the echinocandins anidulafungin, caspofungin and micafungin. J Clin Microbiol, v. 46, p. 2155-9, 2008.

50. PAPPAS, P. G. et al. The NIAID Mycoses Study Group: a prospective observatinal study of candidemia, epidemiology, therapy, and influences on mortality in hospitalized adult and pediatric patients. Clin Infect Dis, v. 37, p. 634-43. 2003.

51. RAMAGE, G. et al. Characteristics of biofilm formation by Candida albicans. Rev Iberoam Micol, v. 18, p. 163-70, 2001.

52. RESENDE, J. C. P. et al. Phenotypic and genotypic identification of Candidaspp. isolated from hospitalized patients. Rev Iberoam Micol, v. 21, p. 24-8, 2004. 
53. REX, J. H. et al. Antifungal susceptibility testing: practical aspects and current challenges. Clin Microbiol Rev, v. 14, p. 643-58, 2001.

54. ROILIDES, E. et al. Candida tropicalis in a neonatal intensive care unit: epidemiologic and molecular analysis of an outbreak of infection with an uncommon neonatal pathogen. J Clin Microbiol, v. 41, p. 735-41, 2003.

55. RORIG, K. C. O.; COLACITE, J.; ABEGG, M. A. Produção de fatores de virulência in vitro por espécies patogênicas do gênero Candida. Rev Soc Bras Med Trop, v. 42, p. 225-7, 2009.

56. SANGUINETTI, M. et al. Evaluation of vitek 2 and rapid yeast plus systems for yeast species identification: experience at a large clinical microbiology laboratory. J Clin Microbiol, v. 45, p. 1343-6, 2007.

57. SIDRIM, J. J. C.; ROCHA, M. F. G. Micologia médica à luz de autores contemporâneos. Rio de Janeiro: Guanabara Koogan, 2004. p. 21, 266.

58. SOLL, D. R. Candida biofilms: is adhesion sexy? Current Biology, v. 18, p. 153-5, 2008.
59. TALARMIN, J. P. et al. Epidemiology of candidemia: a one-year prospective observational study in the west of France. Med Mal Infect, v. 39, p. 877-85, 2009.

60. TAMURA, N. K. et al. Fatores de virulência de Candida spp. isoladas de cateteres venosos e mãos de servidores hospitalares. Rev Soc Bras Med Trop, v. 40, p. 91-3, 2007.

61. VALENZA, G. et al. Evaluation of new colorimetric vitek 2 yeast identification card by use of different source media. J Clin Microbiol, v. 46, p. 3784-7, 2008.

62. VALERIO, H. M.; WEIKERT-OLIVEIRA, R. C.; RESENDE, M. A. Differentiation of Candida species obtained from nosocomial candidemia using RAPD-PCR technique. Rev Soc Bras Med Trop, v. 39, p. 174-8, 2006.

63. VIUDES, A. et al. Candidemia at a terciary-care hospital: epidemiology, treatment, clinical outcome and risk factors for death. Eur J Microbiol Infec Dis, v. 21, p. 767-74, 2002.

64. YIGIT, N.; AKTAS, E. Comparison of the efficacy of different blood médium in determining the hemolytic activity of Candida species. J Mycol Médical, v. 19, p. 110-5, 2009. 